Military Technical College Kobry El-Kobbah, Cairo, Egypt

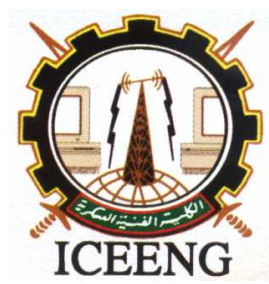

\section{$6^{\text {th }}$ International Conference on Electrical Engineering ICEENG 2008}

\title{
Trends in CMOS image sensor design and technology
}

By

Prof. Pierre Magnan*

\section{$\underline{\text { Abstract: }}$}

After reviewing shortly why CMOS imaging sensors have taken an large part of the imaging market initially held by CCD devices either for consumer or for industrial and even scientific applications, this talk will present how CMOS imagers architectures have evolved to allow for pixel size reduction, to reduce the noise and to increase the readout rate while taking benefit from the possibility of integrating processing functions. Additionally, the move to deep submicron technologies (DSM), required for pixel size reduction or complexity increase, has introduced new challenges to keep and even improve the sensitivity. State of art solutions allowing the DSM CMOS technology to face with the imaging requirements will be described.

* Institut Supérieur de l'Aéronautique et de l'Espace, resulting from the association between SUPAERO and ENSICA institutions 